\title{
Uma interpretação do direito à educação à luz da teoria de Rawls
}

\author{
An Interpretation of the Right to Education in the light of Rawls' Theory
}

Una Interpretación del Derecho a la Educación a la luz de la Teoría de Rawls

MARCOS ROHLING*

\begin{abstract}
$\longrightarrow \diamond$
RESUMO - Este texto tem por propósito discutir o que é um direito à educação a partir da teoria da justiça como equidade de Rawls. Para tanto, o mesmo é dividido em quatro partes: i) em primeiro lugar, discute-se o direito à educação no caso brasileiro, tendo em conta sua previsão constitucional; ii) segue-se avaliando o papel do Estado no pensamento de Rawls, bem como altercam-se as ideias de sociedade e bens primários, vistas como o pano de fundo da educação; iii) explana-se o direito à educação a partir de $T J$, como expectativa legítima, e das modificações realizadas por Rawls à justiça como equidade, apresentando-o como parte do mínimo essencial e, portanto, como direito social constitucional; e, por fim, iv) explora-se o papel e a função da educação tal e qual a teoria de Rawls permite.
\end{abstract}

Palavras-chave - Rawls. Direito à educação. Educação. Justiça como equidade. Teorias da justiça.

\begin{abstract}
This text has the purpose to discuss what is a right to education from the theory of justice as fairness to Rawls. Therefore, it is divided in five parts: i) firstly, discusses the right to education in the Brazilian case in view of constitutional provision; ii) it follows evaluating the state's role in the thought of Rawls and it argues up the ideas of society and primary goods, viewed as the background of education; iii) explains the right to education from $T J$ as legitimate expectation, and the modifications made by Rawls to justice as fairness, presenting it as part of the minimum essential and therefore as social law constitutional; and, finally, iv) explores the role and function of education as is Rawls's theory allows.

Keywords - Rawls. Right to education. Education. Justice as fairness. Theories of justice.

RESUMEN - Este texto tiene el propósito de discutir lo que es un derecho a la educación desde la teoría de la justicia como equidad de Rawls. Con este fin, se divide en cuatro partes: i) en primer lugar, analiza el derecho a la educación en el caso de Brasil, teniendo en cuenta su previsión constitucional; ii) se sigue evaluando el papel del Estado en el pensamiento de Rawls y son discutidas las ideas de sociedad y bienes primarios, las cuales son vistas como el pano de fondo de la educación; iii) se discute a respeito de el derecho a la educación desde TJ, como expectativa legítima, y de los cambios realizados por Rawls a la justicia como equidad, presentándola como parte de lo mínimo essencial y, por lo tanto, como un derecho social constitucional; y, por último, iv) se explora el papel y la función de la educación en la teoría de Rawls.

Palabras clave - Rawls. Derecho a la educación. Educación. Justicia como equidad. Teorías de la justicia.
\end{abstract}

\footnotetext{
* Mestre em Educação pela Universidade Federal de Santa Catarina (Florianópolis, SC, Brasil) e professor no Instituto Federal Catarinense (Videira, SC, Brasil).E-mail: <marcos_roh@yahoo.com.br>.
} 


\section{INTRODUÇÃO}

O direito à educação, como extensível a todos, é um dado recente. Como sugere Gallo, a educação foi, na maior parte da história, uma questão do âmbito privado, sendo o direito à instrução pertencente mais à sociedade do que ao Estado. Quadro esse alterado apenas a partir do século XVIII, quando, com as ideias de sistemas nacionais de educação ligados aos processos políticosociais de consolidação dos Estados nacionais europeus, estes passam a ingerir em questões de cunho educacional (GALLO, 1998, p. 5-7). A educação é vista como um bem que cabe ao Estado ofertar porque destinada para pessoas livres. Nesse sentido, a educação é patrimônio ao qual estão ligados todos os valores criados e vivenciados pela humanidade. ${ }^{1}$

É um pressuposto deste trabalho que a educação seja indubitavelmente uma das necessidades humanas mais prementes, sem a qual inexistiriam as condições de preparo para viver num meio cada vez mais complexo e eivado de falsas expectativas, como aquelas que as sociedades contemporâneas têm apresentado. Sem a educação, estrita e amplamente, as pessoas não teriam elementos para inserir-se na produção cultural de suas sociedades e, por extensão, da humanidade como um todo. Ora, assim, a educação é uma necessidade humana essencial não apenas para o exercício de todos os demais direitos, mas especialmente para a promoção da liberdade e da autonomia individuais, bem como para trazer importantes benefícios de desenvolvimento humano e econômico.

Essa suposição da importância da educação é reforçada quando a perspectiva dimensionada é aquela dos parâmetros internacionais que avaliam o crescimento econômico nacional em termos de crescimento e democratização do acesso à educação. Nesse contexto, não apenas a garantia de acesso, mas a efetivação de uma educação de qualidade em todos os níveis educacionais (infantil, fundamental, média e universitária) para o rompimento com a dependência de produção tecnológica, científica e cultural é considerada relevante. O reconhecimento da necessidade da educação é, para o senso comum, suficiente para garantir o direito a esta. Isso porque é evidente a conexão entre o desenvolvimento das habilidades e dos talentos individuais (como resultado da apropriação da cultura de sua sociedade) e a realização de diferentes projetos racionais de vida, nos termos de Rawls, tal como definido em A Theory of Justice. ${ }^{2}$ No entanto, é preciso algo mais, é preciso uma justificação política para que seja reconhecido como um direito. Isso posto, o direito à educação deve ser visto, no caso do Brasil, a partir dos princípios constitucionais e da ideia de sociedade que se pretende com o correspondente conteúdo formativo, que são os ideais e os objetivos da República, previstos na Constituição da República Federativa do Brasil, de 1988. Embora esse tema seja assunto de estudo do direito educacional (o objeto deste é a sua efetivação do direito à educação; sendo assim, essa efetivação norteia a sua existência) ${ }^{3}$.

Uma vez que a obra de Rawls ${ }^{4}$ seja amplamente conhecida e responsável pelo reavivamento da reflexão política no século XX, pretende-se, à luz do direito à educação na Constituição Federal de 1988, defender o direito à educação nos moldes que a teoria de Rawls permite. Essa teoria é relevante para a discussão por oportunizar uma reflexão que, embora liberal, é comprometida com (a) a dignidade do ser humano e (b) com os direitos individuais. De tal modo que é plausível não apenas orientar a prática brasileira, mas possibilitar a reflexão em torno da mesma. No interior de sua teoria, embora o autor não seja um teórico da educação e nem tenha coerente e organizadamente apresentado reflexões em torno dessa temática, ele referiu-se a ela significativamente, em vários momentos. Assim, através do resgate dessas considerações sobre a educação, pretende-se apontar qual seria o direito à educação a partir da uma interpretação que se paute pelos pressupostos de Rawls.

Suas declarações, que tinham por objeto a educação, embora em número reduzido, refletem a preocupação com a criação de instituições sociais que sejam justas e equitativas no modo como operam dentro da estrutura básica da sociedade. Assim, as ideias de Rawls sobre a educação são um componente de sua ampla reflexão sobre a justiça. Isso posto, o texto estrutura-se do seguinte modo: i) num primeiro momento, discute-se o direito à educação no caso brasileiro, tendo em conta sua previsão constitucional; ii) segue-se, num segundo momento, avaliando-se o papel do Estado no pensamento de Rawls, que, é verdade, dá mais ênfase às instituições e às pessoas; e discutindo-se as idéias de sociedade e bens primários, essenciais para a compreensão da educação e de seu direito em Rawls; iii) num terceiro momento, explanase sobre o direito à educação a partir de $T J$ e à luz das modificações realizadas por Rawls, apresentando-o como parte do mínimo essencial e, portanto, como direito social constitucional; iv) num quarto momento, finalizando, discutem-se o papel e a função da educação tal e qual a teoria de Rawls dimensiona considerar.

\section{O DIREITO À EDUCAÇÃo NA CONSTITUIÇÃo FEDERAL dE 1988}

Num livro bastante instigador e provocante, Bobbio (BOBBIO, 1992) afirma, entre outras coisas, que as pessoas vivem numa era de direitos. A própria discussão acerca do debate sobre os direitos, e em última análise, 
dos direitos dos homens, entre os quais estão os direitos sociais, é, para Bobbio (BOBBIO, 1992, p. 51-2), inspirando-se na posição de Kant acerca do entusiasmo deste quanto à Revolução Francesa, reveladora do progresso moral da humanidade. Isso porque é cada vez mais intensa e ampla, abarcando não mais apenas sociedades particulares, mas, também, todos os povos do globo terrestre.

Em geral, a educação é interpretada como um direito social, pois que seu caráter, apesar de subjetivo, dá-se de modo público. ${ }^{5}$ Esse conceito da educação como um direito público subjetivo, conforme argumenta Horta, recupera o debate iniciado na década de 1930, por Pontes de Miranda e Pedro Kelly, embora seja verdade que, na Constituição de 1934, o direito à educação tenha sido mutilado de sua força imperativa no sentido de cobrar e responsabilizar penalmente o Estado e as autoridades competentes pelo seu oferecimento. Apesar disso, a Constituição de 1988 retoma esse conceito, estabelecendo punições para o caso da não oferta ou de seu oferecimento de forma irregular (HORTA, 1998, p. 17-9; 25-6). Dizer que a educação é um direito público subjetivo é afirmar que todos os cidadãos podem reivindicá-la a qualquer tempo porque seu oferecimento é do interesse de todos.

Não obstante, na atual legislação do Brasil, a educação é um tema considerável, encontrando, por meio da CF88, provimento legal e positivação, como princípios a orientar a produção de normas infraconstitucionais (PAIVA, 2008, p. 69). ${ }^{6}$ Nesse sentido, vale recordar, conforme afirma Bonavides, que evoca a distinção entre princípios e normas realizada por Dworkin, a respeito dos princípios constitucionais: "Os princípios, uma vez constitucionalizados, se fazem a chave de todo o sistema normativo" (BONAVIDES, 2001, p. 231). Para que a constitucionalidade seja, então, assegurada, devem todas as demais formas de legislação pautarem-se por aquilo que pertence à Constituição como princípios constitucionais.

Destarte, de acordo com a vontade do legislador constituinte, no caso brasileiro, a educação, que é um direito social (direito de segunda geração, pode-se dizer), é matéria constitucional por meio de princípios constitucionais. E isso, por seu turno, dá-se mediante a relação entre os diversos pontos básicos que pertencem ao texto constitucional. A Constituição da Republica Federativa do Brasil ${ }^{7}$, de 1988, em nota preambular, afirma a instituição de

[...] um Estado Democrático, destinado a assegurar o exercício dos direitos sociais e individuais, a liberdade, a segurança, o bem-estar, o desenvolvimento, a igualdade e a justiça como valores supremos de uma sociedade fraterna, pluralista e sem preconceitos [...]. (CF88, preâmbulo).
Além disso, o legislador constitucional pretende que a Constituição possua princípios gerais. Dessa sorte, no Título I - Dos Princípios Fundamentais, no artigo 1으, tem-se que:

\begin{abstract}
A República Federativa do Brasil, formada pela união indissolúvel dos Estados e Municípios e do Distrito Federal, constitui-se em Estado Democrático de Direito e tem como fundamentos: I - a soberania; II - a cidadania; III - a dignidade da pessoa humana; IV - os valores sociais do trabalho e da livre iniciativa (CF88, Título I - Dos Princípios Fundamentais, artigo $\left.1^{\circ}\right)$.
\end{abstract}

Esse mesmo legislador constitucional, com o fito de esclarecer os princípios inseridos na lei magna, no artigo $3^{\circ}$, elucida abertamente a constituição dos objetivos fundamentais da República Federativa do Brasil para a construção de uma sociedade livre, justa e solidária. Do mesmo modo, no Título II, indica os direitos e garantias fundamentais do cidadão, dispondo, no artigo $5^{\circ}$, os direitos e deveres individuais e coletivos. Especialmente no caput desse artigo 5o, afirmou o legislador constitucional o princípio da isonomia, pelo qual todos, diante da lei, são iguais. Assim, legifera:

Todos são iguais perante a lei, sem distinção de qualquer natureza, garantindo-se aos brasileiros e aos estrangeiros residentes no País a inviolabilidade do direito à vida, à liberdade, à igualdade [...] (CF88, Título II - Dos Direitos e Garantias Fundamentais, Capítulo I - Dos Direitos e Deveres Individuais e Coletivos, artigo $5^{\circ}$, caput).

Ademais dessa afirmação do caráter isonômico, no caput do artigo $6^{\circ}$, afirma que

São direitos sociais a educação, a saúde, o trabalho, a moradia, o lazer, a segurança, a previdência social, a proteção à maternidade e à infância, a assistência dos desamparados, na forma dessa Constituição (CF88, Título II - Dos Direitos e Garantias Fundamentais, Capítulo II - Dos Direitos Sociais, artigo 6ㅇ, caput).

Ora, a educação figura, então, como um dos direitos sociais que tem isonomicamente as pessoas diante do Estado, dentro dos limites territoriais que definem o Estado da República Federativa do Brasil, por meio de sua Constituição Federal. A esse respeito, insignes juristas brasileiros interpretam os direitos sociais na legislação brasileira, especialmente em nível constitucional, como um ganho e uma conquista dentro daquilo que, convencionalmente, chamam-se direitos de segunda geração. Entre esses, está Alexandre de Moraes, para o qual 
[...] Direitos sociais são direitos fundamentais do homem, que se caracterizam como verdadeiras liberdades positivas, de observância obrigatória em um Estado Social de Direito, tendo por finalidade a melhoria das condições de vida ao hipo-suficiente, visando à concretização da igualdade social, e são consagrados como fundamentos do Estado Democrático, pelo artigo $1^{\circ}$ da Constituição Federal (MORAES, 2003).

Contudo, a educação requer, para sua efetivação, ação conjunta e solidária, por meio da qual Estado e sociedade passam a ser parceiros em prol de um projeto muito mais amplo, a saber, a implementação da educação. Desse modo, estabelece o legislador constituinte que:

A educação, direito de todos e dever do Estado e da família, será promovida e incentivada com a colaboração da sociedade, visando ao pleno desenvolvimento da pessoa, seu preparo para o exercício da cidadania e sua qualificação para o trabalho (CF88, artigo 205, caput).

No artigo 208, estabelece-se o sentido desse dever que tem o Estado para com a educação de seus cidadãos. Assim, estabelece o legislador constitucional, in verbis:

Art. 208. O dever do Estado com a educação será efetivado mediante a garantia de:

I - educação básica obrigatória e gratuita dos 4 (quatro) aos 17 (dezessete) anos de idade, assegurada inclusive sua oferta gratuita para todos os que a ela não tiveram acesso na idade própria;

II - progressiva universalização do ensino médio gratuito;

III - atendimento educacional especializado aos portadores de deficiência, preferencialmente na rede regular de ensino;

IV - educação infantil, em creche e pré-escola, às crianças até 5 (cinco) anos de idade;

$\mathrm{V}$ - acesso aos níveis mais elevados do ensino, da pesquisa e da criação artística, segundo a capacidade de cada um;

VI - oferta de ensino noturno regular, adequado às condições do educando;

VII - atendimento ao educando, em todas as etapas da educação básica, por meio de programas suplementares de material didático-escolar, transporte, alimentação e assistência à saúde.

$\S 1$ o O acesso ao ensino obrigatório e gratuito é direito público subjetivo.

$\S 2^{\circ}$ O não-oferecimento do ensino obrigatório pelo Poder Público, ou sua oferta irregular, importa responsabilidade da autoridade competente.

$\S 3^{\circ}$ Compete ao Poder Público recensear os educandos no ensino fundamental, fazer-lhes a chamada e zelar, junto aos pais ou responsáveis, pela frequência à Escola (CF88, Título VIII - Da Ordem Social,
Capítulo III - Da Educação, Da Cultura e do Desporto, Seção I, Da Educação, artigo 208).

É interessante notar que, ao positivar esses princípios endereçados principalmente à legislação educacional, o legislador constitucional obrigou o Estado a adotar comportamentos e instituições necessários para a sua concretização. A esse respeito, Barcellos argumenta que a educação, no texto constitucional, é vista

[...] como uma atividade prioritária do Estado, pela qual se pode promover o pleno desenvolvimento da pessoa, seu preparo para o exercício da cidadania e sua qualificação para o trabalho. Não é preciso repisar que a educação constitui, modernamente, pressuposto básico para a participação no âmbito do Estado, para o exercício da cidadania e para o ingresso no mercado produtivo. A decisão consciente a respeito do voto em cada eleição, a informação acerca dos direitos mais elementares [...], o acesso ao mercado de trabalho, tudo isso depende hoje, em larga medida, da educação formal (BARCELLOS, 2004, p. 151-2).

Essa questão justamente traduz a preocupação pelo significado da educação na Constituição. E, mais à frente, essa autora manifesta claramente a crítica à opção do legislador constituinte pelo que quer dizer educação no texto constitucional. A sua crítica vai no sentido tal que, no mundo contemporâneo, em que o mercado demanda cada vez níveis mais elevados de formação, apenas o ensino fundamental não é satisfatório para essas exigências formativas, tendo em vista a igualdade de chances para os indivíduos (BARCELLOS, 2004, p. 157). ${ }^{8}$

Em direção semelhante, a respeito da educação, considerando as três finalidades competentes ao Estado, apontadas pela Constituição de 1988 [que seriam: (i) o pleno desenvolvimento da pessoa; (ii) seu preparo para o exercício da cidadania; e (iii) a qualificação para o mundo do trabalho], remetendo-se ao artigo 21 , da Lei no 9.394/96 (LDB), Messeder afirma: i) que esse desenvolvimento pleno da pessoa significa permitir (não asseguradamente) ao indivíduo percorrer o caminho da educação básica à educação superior; ii) que o exercício da cidadania (que engloba todos os direitos políticos) depende do grau de conhecimento de que dispõe o indivíduo, para os quais é necessário: a) conhecimentos de artes; b) conhecimentos de filosofia e sociologia; c) atividades físicas esportivas, não competitivas, que visam a fins recreativos; d) domínio de linguagens (sobretudo, da língua portuguesa, destacando sua importância para a educação tecnológica, científica, das letras e das artes, bem como do processo histórico de transformação da sociedade e da cultura), as quais possibilitam o desenvolvimento da capacidade de aprender pela leitura, 
pela escrita e pelo cálculo; e) conhecimentos de cultura religiosa, os quais devem respeitar a diversidade cultural religiosa do Brasil, sem proselitismos; e iii) preparação para o exercício do trabalho, embora frisando que apenas a modalidade de ensino fundamental seja efetivamente obrigatória no Brasil (MESSEDER, 2010, p. 5-15).

Cabe, então, em face do significado da educação na Constituição Federal, questionar se, de fato, essa noção dá conta das expectativas de cidadãos os quais possuam a mesma dignidade perante o Estado e demais instituições que o personificam. Nesse sentido, a concepção de Rawls que considera as pessoas imerecedoras dos talentos naturais, bem como aquela de acordo com a qual a justiça deve ser a principal virtude das instituições sociais, é inspiradora para pensar o direito à educação do mesmo modo que o papel que tem a sociedade nesse processo.

\section{PAPEL DO ESTADO NO PENSAMENTO DE RAWLS}

É preciso dizer, antes de qualquer coisa, que Rawls não é um teórico do Estado. Como liberal, enfatiza, antes, (a) o papel que têm os indivíduos, destinatários de direitos e deveres que cabe às instituições respeitar e assegurar; e (b) a função das próprias instituições na realização da justiça, as quais indubitavelmente são aquelas que formam um Estado. A ênfase do autor nas instituições talvez possa ser explicada em razão da ação que elas tenham mais como associações de pessoas do que propriamente como representações estatais. É interessante notar que a própria ideia de Estado remete a essa ideia, porquanto Rawls considerá-lo, dados os princípios de justiça, como uma "associação constituída de pessoas livres e iguais" e que, ao exercer o seu poder de tal forma a respeitar o espaço individual e particular da busca de suas próprias crenças, valores e interesses, "[...] atua como agente dos cidadãos e satisfaz as exigências da concepção pública de justiça desses mesmos cidadãos" (RAWLS, 2009, §34, p. 261).

O Estado é, então, uma associação de pessoas com o monopólio do direito legal dentro da qual todas as demais associações realizam as suas atividades e que, nesse sentido, deve assegurar interesses fundamentais para todas estas, tendo em vista a sua abrangência em relação a todas as associações privadas (ROHLING e VOLPATO DUTRA, 2011, p. 74-5). Na mesma linha, Navarro afirma que o Estado, na visão de Rawls, é uma instituição que deve zelar pela equidade no sentido de que mantenha as condições indispensáveis para que cada qual possa perseguir seus interesses e cumprir com as suas obrigações, tal como as entenda por si mesmo. O próprio direito estatal de manter a ordem pública é derivado dessa finalidade de equidade, a qual, como entende Rawls, as pessoas aceitariam numa situação inicial de igualdade (NAVARRO, 1999, p. 23). Além disso, como precisamente esclarece Cherques (CHERQUES, 2011, 557-8), Rawls

[...] confere ao Estado responsabilidades no fornecimento de bens públicos e no controle das instituições responsáveis pelas liberdades individuais e coletivas e pela distribuição equitativa desses bens. Prega também a redistribuição compensatória: os que recebem maiores vantagens têm o dever de compensar a parcela maior recebida em decorrência do que a sociedade lhe proporcionou (por exemplo, impostos progressivos).

Num texto interessante, Grueso (1997, p. 91) afirma que a teoria de Rawls permite identificar algumas condições que complementam o perfil do Estado que subjaz a questão da justiça distributiva. Esses qualificadores, por assim dizer, que se encontram arrolados ao logo do $\S 43$ (RAWLS, 2009, § 43, p. 342-3) e que aparecem no artigo Distributive Justice, de 1967, são, pois, os seguintes: i) a estrutura social está controlada por uma constituição justa que assegura as diversas liberdades que definem a condição de igual cidadania; ii) a ordem jurídica é administrada mediante o princípio da legalidade; iii) existem as liberdades de pensamento e de consciência; iv) deve haver um processo político justo para eleger governos, bem como os responsáveis pela criação de leis justas; v) o governo deve assegurar a todos igualdade de oportunidades no que diz respeito à educação; vi) o Estado deve assegurar e impor igualdade de oportunidades em empresas comerciais e na livre escolha de ocupação (para esse objetivo, deve vigiar o mundo dos negócios e evitar que se estabeleçam barreiras e restrições nos mercados e nas posições desejáveis); vii) deve garantir um mínimo social, o qual deve ser realizado mediante subsídios familiares e pagamentos especiais em épocas de desemprego, ou, ainda, mediante um imposto negativo sobre a renda.

Esse Estado proposto por Rawls, ou pelo menos com o qual sua teoria permite interconexão, é um Estado ao mesmo tempo social e liberal: é liberal porque reconhece a prioridade da liberdade, e é social porque é comprometido radicalmente com a equidade das liberdades individuais. Não obstante essa consideração, inspirando-se no $\S 43$ de $T J$, Felipe (2000, p. 154-5) sustenta que o autor reconhece as seguintes funções sociais como sendo as de um Estado que se pretenda justo. Segundo a autora, o Estado tem: i) a função de aferição de preços a qual assegura a oferta competitiva dos mesmos de tal modo a favorecer a todos; ii) a função de estabilização por meio da qual registra a oferta de empregos e de mão de obra disponíveis, intercambiando os interesses que são nessas áreas expressos, de empregar e de ser 
empregado, e o que dela resulta, o pleno emprego para a produção e a oferta de todos os bens essenciais; iii) a função de transferência que estabelece o mínimo de bens a serem socialmente garantidos a todos, sob pena de se cristalizarem desigualdade sociais gritantes entre as pessoas (tendo em vista que as duas funções anteriores não dão conta dessa necessidade, vale dizer, a de suprir as necessidades que colocam em risco a vida e a integridade da pessoa menos favorecida, em termos naturais, acidentais, social familiares; iv) a função distributiva pela qual há a previsão da fixação de tributos sobre heranças e doações, e a cobrança de impostos proporcionais sobre as despesas (como a autora faz ver, para Rawls o imposto sobre consumo é mais adequado do que sobre os salários). A função de distribuição, por meio de suas duas cobranças, é necessária para o Estado justo, porquanto existir a necessidade contínua do custeio de programas destinados a recompensar aqueles que por razões alheias à sua vontade ficam de fora do sistema produtivo e da possibilidade de alcançar os bens primários necessários à preservação da qualidade de vida; e, finalmente, v) a função de intercâmbio, a qual garante o atrelamento de todas as novas propostas de gastos públicos, não apenas à indicação de fonte da qual sairão os recursos, como, ainda, da aprovação por ampla maioria ou por unanimidade das novas despesas dos governos.

Disso, segue-se que o Estado age prioritariamente na distribuição. Como, então, pensar o direito à educação nesse contexto teórico? Ou, mais especificamente, partindo-se da indagação que faz Sacavino, ao falar do direito humano a educação: como pensar o direito à educação num mundo e num país marcados pelo contraste de recursos, oportunidades e direitos, onde, cada vez mais, uns poucos concentram muito e a maioria das pessoas sofre de escassez e exclusão? Não se trata, como pondera, apenas de recursos financeiros, mas de outros bens e direitos, como espaço de participação, voz ativa, poder de decisão, informação e oportunidade de aprendizagem (SACAVINO, 2006, p. 457).

Tendo em mente essas questões, no que se segue, serão retomadas algumas ideias de Rawls, tais como as de sociedade bem ordenada e bens primários para mais bem contextualizar o direito à educação, partindo-se da ótica de Rawls.

\section{SOCIEDADE BEM ORDENADA E BENS PRIMÁRIOS: O PANO DE FUNDO DA EDUCAÇÃO}

Preliminarmente, na linha do que aduz Rawls, a educação será entendida como o desenvolvimento e o treinamento de habilidades e aptidões individuais. Assim, para que se compreenda o seu significado e o seu papel em $T J$, é crucial entender os conceitos de sociedade bem ordenada e bens primários, tendo em vista que é à luz deles que a educação ganha contornos. A sociedade bem ordenada, para o autor, é aquela que é regulada por uma concepção pública de justiça, de tal modo que todos aceitam e sabem que os outros também aceitam os mesmos princípios de justiça da mesma maneira que as principais instituições sociais têm suas diretrizes orientadas pela mesma concepção, fato este igualmente do conhecimento de todos (RAWLS, 2009, § 69, p. 560). Em PL, Rawls reformula brevemente essa ideia, tornando-a compatível com o liberalismo político. Assim, tal sociedade é tal que seja regulada por uma concepção política e pública de justiça na qual todos aceitam, e sabem que os outros aceitam, tanto os mesmos princípios de justiça quanto as principais instituições políticas e sociais, bem como seus cidadãos têm um senso efetivo de justiça que os leva a agir de acordo com as instituições da estrutura básica consideradas justas (RAWLS, 2000, p. 78-9).

É significativo ter presente que o ponto importante para qualquer teoria da educação que parta dos pressupostos rawlsianos, isto é, que seja derivada dos princípios de justiça, é o fato social/psicológico segundo o qual as pessoas preferem bens primários a tê-los em menor quantidade, para o qual os princípios de justiça são mais adequados (RAWLS, 2009, § 25, p. 211). Os bens primários podem ser conceituados, em sentido amplo, como direitos, liberdades e oportunidades, assim como renda e riqueza, e o senso do próprio valor - a autoestima. Como sustenta o autor, os bens primários

[...] são coisas que se supõe que um homem racional deseja, não importa o que mais ele deseje. Independentemente de quais sejam em detalhes os planos racionais de um indivíduo, supõem-se que há várias coisas das quais ele preferiria ter mais a ter menos. Tendo uma maior quantidade desses bens, os homens podem geralmente estar seguros de obter um maior sucesso na realização de suas intenções e na promoção de seus objetivos, quaisquer que sejam eles (RAWLS, 2009, § 15, p. 97-8).

Em escritos posteriores (RAWLS, 2000, p. 228), essa lista é refeita e apresentada do seguinte modo, em cinco categorias, as quais podem ser aumentadas:

a) direitos e liberdades fundamentais, que constituem uma lista;

b) liberdade de movimento e livre escolha de ocupação num contexto de oportunidades diversificadas;

c) poderes e prerrogativas de cargos e posições de responsabilidade nas instituições políticas e econômicas da estrutura básica;

d) renda e riqueza;

e) bases sociais do autorespeito. 
Ora, vistos desse ângulo, os bens primários seriam, para Rawls, não apenas coisas, mas aqueles os quais é racional querer, independentemente do que mais se queira, já que são, em geral, necessários para a estruturação e execução de um plano racional de vida (RAWLS, 2009, $\S 66$, p. 479-80). Assim posto, em $T J$, são necessidades que os cidadãos, como pessoas livres e iguais, requerem para o desenvolvimento de seus planos racionais de vida e, como tais, têm conhecimento disso em suas considerações desde o interior da posição original, enquanto sabem que os princípios de justiça devem assegurar-lhes um número suficiente destes em sua vida de cidadãos (ROHLING, 2012, p. 129).

$\mathrm{Na}$ posição original, as pessoas deliberam racionalmente sobre esses bens, escolhendo o meio mais eficaz para que atinjam o fim determinado. Nesse sentido, o desenvolvimento dos bens primários está intimamente ligado aos próprios poderes da racionalidade deliberativa, pois, para Rawls, "o nosso bem é definido pelo plano de vida que adotaríamos com plena racionalidade deliberativa se o futuro fosse previsto com precisão e adequadamente percebido na imaginação" (RAWLS, 2009, § 64, p. 521). Sendo assim, como pontua Johnston, para que a educação seja justa, ela deve ser cobrada não somente com o cultivo desses bens, mas com o desenvolvimento do caráter deliberativo necessário para reconhecê-los e garantir sua aquisição (JOHNSTON, 2005, p.205). É esse processo do raciocínio deliberativo que fornece a base para o procedimentalismo que conduz aos dois princípios de justiça no interior da posição original.

A educação, dentro do esquema da teoria da justiça proposta por Rawls, preocupa-se com o oferecimento de oportunidades e com a distribuição de todos os bens primários, mas favorece uns sobre outros. Isso se explica em virtude de que, para Rawls, eles não têm hierarquicamente o mesmo valor e, evidentemente, uns mais que outros, contribuem para a deliberação em torno dos princípios de justiça. Nessa senda, por exemplo, entende-se a importância que o autor destina ao bem social primário da autoestima (ROHLING, 2012, p. 130). Como aponta Johnston, a autoestima é duplamente importante: não só é um bem primário que, junto com os outros bens primários, fornece a base para os princípios de justiça, mas ela própria é uma condição necessária para o desenvolvimento moral no sentido exigido por aqueles que estão a deliberar de acordo com os princípios (JOHNSTON, 2005, p. 206).

\section{LOTERIA NATURAL, JUSTIÇA DISTRIBUTIVA E EDUCAÇÃO: RAWLS E O DIREITO À EDUCAÇÃo}

Considerando-se a obra de Rawls como um todo, o direito à educação é passível de ser visto a partir de duas perspectivas: i) aquela de $T J$ e ii) aquela que resulta das reformulações da teoria da justiça como equidade. Em $T J$, o direito à educação é visto considerando-se, de modo inicial, principalmente a crítica que Rawls faz aos conceitos de mérito moral e aos condicionamentos da loteria natural e da sociedade de tal modo que o princípio de oportunidade, conjugado com o princípio da diferença, deve criar condições mais equitativas. Além disso, do esquema de arranjos econômicos, ter um direito é resultado de expectativas legítimas, donde se segue que o direito à educação resulta de uma expectativa legítima em relação à educação. Por sua vez, nas considerações após $T J$, o direito à educação é visto como parte do mínimo social, o qual é um elemento constitucional essencial. No entanto, tanto num como noutro momento, a educação é vista como crucial e especialmente relacionada ao exercício de direitos e liberdades básicas. Daí sua relevância.

\subsection{O direito à educação como expectativa legítima}

Considerar o direito à educação a partir de Rawls exige que se estabeleça uma distinção entre bens naturais e bens sociais, distinção essa que caracteriza esses últimos pela indivisibilidade e pelo caráter público (RAWLS, 2009, $\S 42$, p. 331). A esse respeito, um elemento que se quer sopesar é aquele relativo às contingências individuais, o qual ganha expressão nos termos da relação entre a loteria natural e a educação, isto é, a distribuição natural dos talentos e a educação. Rawls mesmo não aborda tal questão nesses termos, mas é possível derivar algumas importantes considerações acerca dessa temática a partir daquilo que, laconicamente, aduz a respeito da questão (WEITZ, 1993, p. 421-34).

A ideia central do argumento de Rawls é que as pessoas não são merecedoras dos talentos e aptidões que contingentemente elas têm. Seguindo esse raciocínio, e tendo em vista que os indivíduos têm uma inviolabilidade calcada na justiça a qual nem mesmo o bem-estar da sociedade como um todo pode sobrepujar (RAWLS, $2009, \S 1$, p. 4), pode-se arguir que não seria estranho defender que a educação deva ser de tal modo estruturada a diminuir as disparidades entre os indivíduos. Cabe dizer, então, que o acesso à educação deve possibilitar a todos o alcance de posições sociais relevantes, como preceituam as duas partes do segundo princípio de justiça (ROHLING, 2012, p. 132). Além disso, deve-se ter em conta que, para Rawls,

a distribuição não é justa nem injusta; nem é injusto que se nasça em determinada posição social. Isso são meros fatos naturais. Justo ou injusto é o modo como as instituições lidam com esses fatos. [...] Os dois princípios são um modo equitativo de enfrentar a arbitrariedade da sorte; e, por mais imperfeitas 
que possam ser em outros aspectos, as instituições que atendem a esses princípios são justas (RAWLS, 2009, §17, p. 122).

Uma leitura atenta de $T J$ faz perceber que, para o filósofo, conforme indica van Parijs, "os talentos inatos não são merecidos por aqueles que com eles são dotados, e constituem, por isso mesmo, um fator de desigualdade moralmente arbitrário" (Van PARIJS, 1997, p. 168) e que, nesse sentido, "ninguém merece sua maior capacidade natural nem um ponto de partida mais favorável na sociedade" (RAWLS, 2009, §17, p. 121). Afirmar isso significa rechaçar o mérito e, evidentemente, um posicionamento com importantes implicações para a educação. Mas o que se pretende pontuar é que, se o mérito é rejeitado, pois que os indivíduos não são merecedores dos seus talentos inatos ou sociais com os quais são dotados, a educação, sendo o exercício e treinamento dessas habilidades, é tal que as injustiças e desigualdades, em virtude da desigualdade natural da dotação de talentos, moralmente arbitrária, são dirimidas, tendo como referencial a posição do mais mal colocado socialmente (ROHLING, 2012, p. 132).

Mas, efetivamente, como se deveria pensar o direito à educação? Como é evidente, Rawls implicitamente fala que as pessoas devem claramente ter acesso à educação como forma de se assegurar a justiça das instituições e do envolvimento na realização das liberdades asseguradas pelo primeiro princípio. Mas o que seria ter um direito segundo Rawls? A esse respeito, Martin sugere que, para Rawls, ter um direito é poder exigir das instituições o recebimento justo de bens primários sociais em virtude de uma expectativa legítima. Nesse sentido, prossegue, a justificação de um direito implica estabelecer a legitimidade da expectativa no âmbito da justificação em condições de equilíbrio reflexivo. $\mathrm{O}$ interessante, nessa leitura, é que surpreendentemente as liberdades, como bens primários sociais, poderiam ser chamadas de direitos, é verdade que não do ponto de vista da posição original, mas sim sob a perspectiva dos arranjos institucionais impostos pela justiça (MARTIN, 1985, p. 21-31).

De mais a mais, esse autor observa que o termo direito é usado por Rawls de tal modo a causar enganos. Não obstante, sugere que é empregado em dois sentidos: (i) como a mais extensa liberdade possível compatível com a de todos os membros - nos termos do primeiro princípio - e (ii) como liberdades básicas. Ora, se esse é o caso, ter um direito, ou, antes, reconhecer um direito se relaciona justamente com a força dos argumentos que podem ser direcionados a ele na posição original (MARTIN, 1985, p. 21-31). Na verdade, é interessante perceber que o próprio Rawls, no $\S 48$, de $T J$, afirma que as expectativas legítimas são, por assim dizer, o direito que os indivíduos adquirem por realizarem certas tarefas que são encorajadas pelos arranjos institucionais existentes, e o avesso dos princípios da equidade e dos deveres naturais (RAWLS, 2009, §48, p. 389). Sendo assim, os direitos devem ser entendidos como expectativas individuais legítimas do que se receberá numa distribuição justa dos bens sociais primários, de tal forma que a concepção de direito é dada por aquilo que se pode garantir (ARANGO, 2005, p. 142). ${ }^{9}$

Essa questão, evidentemente, trata do problema da justiça distributiva, o qual foi cuidadosamente visto por Rawls, sendo considerado mesmo como central de sua teoria da justiça (FLEISCHACKER, 2006, p. 162). Cumpre dizer que o segundo princípio de justiça orienta a distribuição dos benefícios e vantagens oriundos da cooperação social e que, lexicalmente, deve-se respeitar o primeiro princípio de justiça, que preceitua a igual liberdade. Todavia, "a distribuição de renda e riqueza, e de cargos de autoridade e responsabilidade, deve ser compatível tanto com as liberdades fundamentais quanto com a igualdade de oportunidades" (RAWLS, 2009, $\S 13$, p.91). Assim, entende o filósofo que a injustiça se caracteriza nas desigualdades sociais que não sejam vantajosas para todos.

Presumindo-se a existência das instituições que requisitam os princípios da liberdade igual (ok?) e da igualdade equitativa de oportunidades, Rawls observa que as expectativas mais elevadas daqueles os quais estão em melhor situação serão justas se, e somente se, fizerem parte de um esquema que eleve as expectativas dos membros em condições menos favoráveis. A justiça, portanto, das expectativas dos socialmente mais bem situados relaciona-se diretamente com o grau de elevação das expectativas daqueles que estão em posições mais desfavorecidas, de tal modo que as desigualdades serão justas se - enfatize-se o condicional - forem vantajosas para os menos favorecidos (RAWLS, 2009, § 13, p.91). Nesse contexto, como afirma Freeman, o governo, embora não precise exclusivamente monopolizar o oferecimento do serviço, deve oportunizar o acesso à educação como uma forma de dirimir as desigualdades sociais (2007, p. 90).

De modo mais concreto, no modelo liberal de Rawls, a educação está especialmente relacionada ao segundo princípio de justiça e às suas duas partes. Para entender essa relação, é importante recordá-las: a primeira, chamada de princípio da igualdade equitativa de oportunidades, em oposição à igualdade formal de oportunidades do liberalismo clássico, preceitua a igualdade de oportunidades para aqueles com talentos e habilidades semelhantes, no seio de uma sociedade bem ordenada. Freeman aduz que Rawls distingue a ideia liberal clássica das posições abertas - igualdade formal de oportunidades 
- da igualdade equitativa de oportunidades, uma ideia mais substantiva de igualdade, pois que, além de prevenir a discriminação e aplicação das posições abertas, procura corrigir a desvantagem social $(2007$, p. 89$)$. Nessa senda, o princípio da igualdade de oportunidades é um corretor de diferenças de classe social

[...] aqueles que têm capacidades e habilidades similares devem ter oportunidades de vida. Mais especificamente, presumindo-se que haja uma distribuição de dotes naturais, os que estão no mesmo nível de talento e capacidade, e têm a mesma disposição para usá-los, devem ter as mesmas perspectivas de êxito, seja qual for seu lugar inicial no sistema social. Em todos os setores da sociedade deve haver perspectivas mais ou menos iguais de cultura e realizações para todos os que têm motivação e talentos semelhantes. As expectativas dos que têm as mesmas capacidades e aspirações não devem sofrer influência da classe social a qual pertencem (RAWLS, 2009, § 12, p. 87-8).

Não obstante, em $T J$, Rawls estabelece somente dois requisitos institucionais impostos pelo princípio da igual oportunidade, a saber, a prevenção da acumulação de bens e riquezas e a manutenção de oportunidades iguais de educação para todos $(2009, \S 12$, p. 88). Por conseguinte, mediante ações institucionais, decorre desse princípio o dever de a sociedade oferecer oportunidades iguais de educação para todos, sobretudo para aqueles com talentos e dotes naturais semelhantes que, por conta de condição social, estão em posições desfavoráveis para a competição com aqueles que, embora tendo talentos semelhantes, encontram-se socialmente favorecidos. Por sua vez, sublinhe-se que não dimana dos princípios de justiça a exigência de um sistema público de educação, pois um sistema privado é perfeitamente compatível com os requisitos do princípio da igualdade equitativa de oportunidades, desde que respeite os requisitos institucionais impostos por Rawls (ROHLING, 2012, p. 133-4).

$\mathrm{Na}$ teoria de Rawls, a educação (e seu consequente direito) é vista como um elemento crucial para dirimir as desigualdades sociais e permitir, entre aqueles com talentos semelhantes, uma competição justa, independentemente de contingências sociais e naturais. Assim é, porque, se por um lado o princípio da igualdade de oportunidades estabelece que a educação deva fazer desaparecer as diferenças de ordem social, por outro lado, na justice as fairness, tal princípio opera sempre em harmonia com o principio da diferença. Isso garante uma distribuição do produto da cooperação social que seja justa para todos, pois que maximiza as expectativas dos mais mal colocados no sistema social, inclusive no oferecimento de oportunidades formativas e educacionais (ROHLING, 2012, p. 134-5).
Desse modo, como um elemento de justificação do princípio da igualdade equitativa de oportunidades, a educação visa a reforçar nos indivíduos, por meio do igualitarismo, o senso do próprio valor e as bases sociais do autorrespeito para todos, sem levar em conta as suas capacidades naturais, e não puramente o avanço tecnológico e o estabelecimento de uma sociedade meritocrática para a maior realização da eficiência produtiva ou de valores perfeccionistas. ${ }^{10}$ Valores esses que privilegiam os bem nascidos. Para Rawls, quando os indivíduos são incapazes de desenvolver plenamente suas capacidades, não importa quão modestas sejam e quando as posições não estão abertas numa base justa para todos,

[...] os excluídos estariam certos de se sentirem injustiçados, mesmo que se beneficiassem dos esforços maiores daqueles autorizados a ocupá-los [cargos]. Sua queixa seria justificada não só porque foram excluídos de certas recompensas externas de cargos, mas também porque foram impedidos de vivenciar a realização pessoal resultante do exercício competente e dedicado de deveres sociais. Seriam privados de uma das principais formas de bem humano (RAWLS, 2009, § 14, p. 102).

Eis que, ao ser conjugado com o princípio da diferença, o princípio da igualdade equitativa de oportunidades, respeitando a prioridade lexical, estabelece maiores benefícios educacionais para os que estão socialmente mais mal colocados no esquema social, reforçando, nos indivíduos, por certo, principalmente o bem primário do autorrespeito. Mas, mais que isso: o direito à educação, como direito social, não deriva do primeiro princípio, como uma liberdade básica ou algo do gênero. É derivado, isso sim, da relação estabelecida entre as duas partes do segundo princípio: o das oportunidades iguais e o da diferença. Não há, por isso, uma igualdade na distribuição desses recursos, como é o caso do conteúdo do primeiro princípio. Não apenas a educação, mas a alimentação, a saúde, o trabalho, entre outros direitos denominados sociais, têm uma distribuição desigual e, portanto, não podem ser considerados como direitos constitucionais, no sentido de que pertenceriam a uma carta de direitos que afirma sua igual distribuição entre os membros de uma sociedade, pelo menos, na ótica de Rawls em TJ. ${ }^{11}$

\subsection{O direito à educação como parte do mínimo social e dos direitos constitucionais sociais}

Nas sucessivas reformulações da teoria da justiça como equidade que Rawls fez após a publicação de $T J$, principalmente em $O$ Liberalismo Político e Justiça como Equidade: uma Reformulação, o autor amplia, por assim dizer, o leque dos direitos abarcados pelos dois 
princípios. Inclui, nesse sentido, certos direitos sociais, os direitos constitucionais sociais (MICHELMAN, 1979), ao mesmo tempo em que limita essa teoria ao âmbito do político. Entre esses direitos sociais, abarcados pelos princípios de justiça, estão aqueles relativos à educação, de tal sorte que esse quadro de direitos sofre, também, alterações significativas. ${ }^{12}$

No que respeita exclusivamente à questão do direito à educação, pode-se dizer que esta passa a pertencer ao conjunto de direitos sem os quais não se podem exercer os demais direitos e liberdades fundamentais, integrando, assim, o mínimo social (não sem grandes problemas). A ideia básica dessa mudança é que os princípios de justiça política que conformam os elementos constitucionais essenciais incluem tanto liberdades básicas como o mínimo social indispensável à satisfação das necessidades básicas das pessoas, tendo em vista permitirem o exercício de seus direitos constitucionais (ARANGO, 2005, p. 153).

Ao reformular sua teoria de algumas críticas, Rawls intenta fazê-lo de tal modo a harmonizar a teoria da justiça como equidade inicialmente exposta em $T J$, com o enfoque político da mesma que resulta na teoria política da justiça de $P L$. No que se refere à justificação de direitos, sobretudo, de direitos constitucionais, o ideal de razão pública é expresso na concepção política de justiça, a qual, por sua vez, divide-se em grupos de princípios (RAWLS, 2000, p. 277-8), a saber: a) os princípios fundamentais que especificam a estrutura geral do Estado e do processo político (tais como as prerrogativas do legislativo, do executivo e do judiciário, bem como o alcance da regra da maioria); e b) os direitos e liberdades fundamentais e iguais de cidadania que maiorias legislativas devem respeitar (entre as quais o direito ao voto e à participação política, a liberdade de consciência, a liberdade de pensamento e de associação do mesmo que as garantias do estado de direito (pensamento incompleto) [império da lei - rule of law]. Ora, são os princípios do segundo tipo que ocupam a atenção de Rawls porque determinam as formas da liberdade, sendo excluídos, portanto, os princípios relacionados à justiça distributiva. ${ }^{13}$ Nesse sentido, o filósofo afirma que

[...] existem quatro motivos para distinguir os elementos constitucionais essenciais especificados pelas liberdades fundamentais dos princípios que governam as desigualdades sociais e econômicas.

a) Os dois tipos de princípios especificam papéis diferentes para a estrutura básica;

b) É mais urgente estabelecer os elementos essenciais que lidam com as liberdades fundamentais;

c) É muito mais fácil atestar se esses elementos essenciais estão sendo realizados;

d) É muito mais fácil chegar a uma concordância sobre quais devem ser os direitos e liberdades fundamentais, é claro que não em todos os detalhes, mas no que se refere às linhas mestras.

Essas considerações explicam por que a liberdade de movimento e a livre escolha de ocupação, e um mínimo social que abarque as necessidades mínimas dos cidadãos, contam como elementos essenciais, ao passo que o princípio da oportunidade equitativa e o princípio da diferença não são considerados como tais (RAWLS, 2000, p. 280).

Nessa conjuntura, o direito à educação é compreendido como parte desse mínimo social, ao qual as pessoas têm direito, porquanto ser fundamental ao exercício das demais liberdades e direitos na ordem social. É verdade que ao lado da alimentação e de outras garantias básicas. E mais: isso revela que esse mínimo social passa a pertencer aos elementos constitucionais essenciais que exigem unicamente a consideração desde a perspectiva política. Essa questão, contudo, não é simples, pois, embora Rawls reconheça o direito constitucional ao mínimo social especificado por meio das necessidades básicas, é também verdade que o autor renuncia à qualificação do mínimo social como um direito fundamental. Arrango assevera que, nesse contexto, o mínimo social especificado pelas necessidades básicas (visto como um elemento constitucional essencial e não como um bem primário) em qualquer caso serve como um momento prévio à distribuição dos bens básicos mediante o processo político (ARANGO, 2005, p 153). Também Weber afirma que, para marcar a estreita relação com a dignidade, esse mínimo não pode ser atrelado apenas à satisfação das necessidades básicas materiais, mas deve visar ao desenvolvimento da pessoa como cidadã. Sob esse aspecto, ressalta que há um avanço com a ideia de bens primários, pois

os direitos à educação básica, à saúde, à alimentação, etc., certamente estão incluídos ou pressupostos no primeiro princípio de justiça. Mas essa lista é completada com outros bens primários do segundo princípio, tal como a igualdade equitativa de oportunidades, para a qual, aliás, é necessária a educação (WEBER, 2013, p. 210).

De fato, para Rawls, dando razão a Michelman, o mínimo social enquanto elemento social envolve a defesa de que, abaixo de certo nível de bem-estar material e social, bem como de treinamento e educação, as pessoas simplesmente não podem participar da sociedade como cidadãs. Tampouco, como cidadãs iguais, não obstante assegurar que não caiba à concepção política da justiça definir o que determina o nível de bem-estar e de educação abaixo do qual isso aconteça $\left(2000\right.$, p. 215). ${ }^{14}$ Disso, segue-se que o direito à educação, como um direito social, é parte integrante do mínimo social, o qual 
permite a participação, o desenvolvimento e o exercício de outras prerrogativas e liberdades básicas afixadas pela concepção política de justiça.

\section{FUNÇÃo E PAPEL dA EDUCAÇÃo}

Cabe indagar, agora, acerca da função que desempenha a educação. Para Rawls, a justiça das instituições caracterizar-se-ia, num sentido, pela igualdade equitativa de oportunidades. Nesse caso, a educação, como instituição social, é encarregada de assegurar a igualdade de oportunidades por meio da redistribuição dos recursos que compete a ela, pois

[...] o princípio da diferença alocaria recursos para a educação, digamos, para elevar as expectativas de longo prazo dos menos favorecidos. Se tal fim for alcançado dando-se mais atenção aos mais talentosos, é permissível; caso contrário, não. E, ao tomar essa decisão, não se deve aferir o valor da educação apenas no tocante à eficiência econômica e ao bem-estar social. Tão ou mais importante é o papel da educação de capacitar uma pessoa a desfrutar da cultura de sua sociedade e participar de suas atividades, e desse modo de proporcionar a cada indivíduo um sentido seguro de seu próprio valor (RAWLS, 2009, § 17, p. 121).

A reflexão sugere, conforme a interpretação de Freeman (FREEMAN, 2007, p. 90-2), que o argumento de Rawls parece exigir que os recursos devam ser comprometidos, em primeiro plano, com os menos favorecidos, de tal modo a lhes elevar a expectativa quanto à realização de seus projetos - e considerem-se planos racionais de vida - dentro da sociedade. Se esse é o caso, então, a educação deve procurar diminuir as desigualdades e essas não devem ser vistas unilateralmente pelo viés da economia ou do bem-estar social, mas, principalmente, pela capacidade de permitir a uma pessoa desfrutar da cultura de sua sociedade, podendo, por conseguinte, participar de suas atividades. Assim sendo, a educação conduziria e reforçaria, no indivíduo, o senso do próprio valor que, como indicado, é um dos principais bens primários, cuja distribuição é orientada pelos princípios de justiça.

$\mathrm{O}$ segundo princípio, como se sabe, estabelece que pessoas que tenham talentos semelhantes não sejam, por contingências sociais, fadadas às piores experiências. Ora, o oferecimento de oportunidades educacionais é um modo de serem diminuídas certas disparidades sociais e de proporcionar o desfrute de uma quantidade maior de bens primários. Conforme salientado, em si mesma, para Rawls, a distribuição natural de talentos não é justa nem injusta, mas tais atribuições são consequências do modo como as instituições lidam com elas. Assim, uma teoria da justiça deve ser tal que dirima essas desigualdades naturalmente arbitrárias, o que se dá mediante o oferecimento de oportunidades educacionais, inclusive, para elevar as expectativas dos menos dotados naturalmente (ROHLING, 2012, p. 146).

Ademais, por meio do oferecimento de oportunidades equitativas de formação educacional, a educação é um elemento que permite o acesso aos bens primários e, de modo especial, à autoestima. O valor da educação, assim, é relacionado e medido exclusivamente por permitir ao indivíduo apropriar-se da cultura de sua sociedade e, pode-se dizer, de toda a produção cultural do tipo humano num sentido bem mais amplo. Assim procedendo, inexoravelmente, reforçará o valor de si mesmo para os indivíduos. Logo, o valor de uma educação de qualidade não está nas cifras que economicamente se podem galgar, mas justamente na medida em que propicia aos membros de certa sociedade apropriar-se de sua produção cultural de tal modo a reforçar, neles mesmos, o sentimento do próprio valor.

Considera-se que essa visão de Rawls é certamente muito positiva e assenta a importância da educação na cultura e na autoestima, e não na formação exclusivamente técnica e preparatória para o trabalho - sem, contudo, excluí-la. Portanto, ao apropriar-se da cultura florescimento humano, tais como a literatura, as tradições musicais e religiosas, as atividades físicas e artísticas, as produções científicas e técnicas, entre outras -, o indivíduo reforça o senso do próprio valor, e mais significativamente persegue seus fins, quaisquer que sejam eles. ${ }^{15}$

Além disso, como efeito da primeira parte do segundo princípio, obtém-se a implicação de que a sociedade tem o dever de oferecer oportunidades iguais de educação para todos. Disso, como se observou, não se segue que o Estado deva primar por um sistema público de ensino. Um sistema privado de educação é perfeitamente compatível com a concepção da justiça como equidade, desde que proporcione oportunidades iguais de educação para todos os membros da sociedade, que dirimam circunstâncias e condicionamentos de ordem social. ${ }^{16}$ Certo é que, compreendendo a educação e, sobretudo, a educação formal, como uma instituição que é parte da estrutura básica da sociedade, ter-se-á o entendimento de que deva preparar o indivíduo para a vida, principalmente, para o exercício de seu papel na sociedade (VALLE, 2010, p. 30). Por essa via, conteúdos que reforcem o valor de si mesmo e que preparem para a cidadania e para o senso de cooperação social e solidariedade estão de acordo com o espírito da proposta da justiça como equidade.

No entanto, a educação cumpre outro papel, qual seja, o de desenvolvimento da autonomia individual. Esse aspecto é realizado quando, ao permitir o treinamento e o aprimoramento dos talentos e aptidões individuais, as pessoas gradualmente vão tendo uma ação refletida 
pelos princípios de justiça, os quais aceitariam como pessoas livres e iguais. Evidentemente, por meio do desenvolvimento do senso de justiça, as pessoas são levadas a aceitar esses princípios e a endossá-los como sendo os que escolheriam numa posição inicial de igualdade (ROHLING, 2012, p. 147). Ora, agir de acordo (e por respeito) com princípios de justiça é, então, agir autonomamente e ter realizado todo o desenvolvimento moral. É verdade que, nesse aspecto, fica clara a influência de Kant e de Rousseau no desenvolvimento moral que Rawls arvora no interior da $T J$.

\section{CONCluSÃo}

O Brasil é um país cuja política econômica e social é filiada à tradição do liberalismo, que, a partir da CF88, imprimiu fortes traços da social democracia e do walfare states. Embora esse seja o caso, é uma lastimável verdade que muitos direitos e garantias constitucionais, apesar de tutelados pelo Estado, não chegam a ser efetivados e, em consequência, os cidadãos ficam privados de seus direitos mínimos essenciais assegurados. Razão pela qual, sem educação, não há como se falar em cidadania. É inegável que nesse contexto e à luz do mesmo, a educação opera como um meio mediante o qual projetos existênciais, racionais, sociais, entre outros, são passíveis de realização, tal como a ideia central externada por Kant: "É somente por meio da educação que o homem pode chegar a ser homem. Não é nada além do que faz dele a educação". ${ }^{17}$ Inobstante, negar o direito à educação é negligenciar os elementos essenciais para uma vida significativa, seja qual for o sentido que cada qual dos cidadãos atribua a ela. Nesse sentido, pode-se concluir que o Estado tem o dever de garantir, consoante o que implicam seus princípios, os direitos fundamentais, de tal modo a proporcionar e a possibilitar aos cidadãos as condições necessárias para o exercício de tais direitos, em virtude do que se deve primar pela igualdade de oportunidades quanto ao oferecimento de educação básica para todos. Nessa direção, a obra de Rawls é um poderoso instrumento para se pensar o direito à educação.

Dito isso, o que se procurou ofertar foi uma justificativa do direito à educação a partir de Rawls, considerando sobremaneira a sua obra máxima. Em A Theory of Justice, o ponto crucial são os princípios de justiça, cuja justificação dá-se mediante a posição original em que a racionalidade das partes opera, tendo em vista a distribuição de uma quantidade maior de bens primários. Justice as fairness se consubstancia nos dois princípios de justiça: o primeiro é o da liberdade igual, ao passo que o segundo é composto de duas partes, a saber: o princípio da igualdade equitativa de oportunidades e o princípio de diferença. A primeira parte do segundo princípio legifera medidas que atenuem, senão façam desaparecer, as desigualdades de ordem social. Assim, esse princípio estabelece que pessoas que tenham talentos semelhantes não sejam, por contingências sociais, fadadas às piores experiências. $\mathrm{O}$ oferecimento de oportunidades educacionais é um modo de se diminuir certas disparidades sociais e proporcionar o desfrute de uma quantidade maior de bens primários. Conforme salientado, em si mesma, a distribuição natural de talentos não é justa ou injusta, mas tais atribuições são consequências da maneira como as instituições lidam com elas. Desse modo, uma teoria da justiça deve dirimir essas desigualdades naturalmente arbitrárias, o que se dá mediante o oferecimento de oportunidades educacionais, inclusive, para elevar as expectativas dos menos dotados naturalmente.

Por meio do oferecimento de oportunidades equitativas de formação educacional, tem-se a educação como um elemento a permitir o acesso aos bens primários, entre os quais a autoestima é o mais importante. $\mathrm{O}$ valor da educação não é medido pela eficiência ou por qualquer bemestar social que possa proporcionar, mas, exclusivamente, por permitir aos indivíduos apropriarem-se da cultura de sua sociedade e de toda a produção cultural humana num foro amplo. Assim, inexoravelmente, reforça o valor de si mesmos, como pessoas morais, para os indivíduos.

Além disso, como efeito da primeira parte do segundo princípio, tem-se a implicação de que a sociedade tem o dever de oferecer oportunidades iguais de educação para todos. Disso, como se observou, não significa que o Estado deva primar por um sistema público de ensino. Em TJ, um sistema de educação privada é perfeitamente compatível com a concepção da justiça como equidade, desde que proporcione oportunidades iguais de educação para todos os membros da sociedade, que dirimam circunstâncias e condicionamentos de ordem social.

O papel da educação é, por certo, realizar a autonomia individual ao permitir o desenvolvimento e o treinamento de habilidades e aptidões individuais, possibilitando que as pessoas tenham uma ação refletida pelos princípios de justiça os quais elas aceitariam como pessoas racionais, livres e iguais. Quando o senso de justiça resulta formado, pode-se dizer que o indivíduo tem, então, realizada a sua autonomia, pois que age de acordo com os princípios que ele mesmo escolhe numa situação inicial de igualdade, o que, em $T J$, corresponde à estabilidade de uma teoria da justiça, pois ela mesma tem condições de gerar sua manutenção.

\section{REFERÊNCIAS}

ARANGO, Rodolfo. John Rawls y los derechos constitucionales. In: BOTERO, Juan. (Org.). Con Rawls y Contra Rawls. Bogotá: Universidad Nacional de Colombia, Unibiblos, 2005. 
BARCELLOS, Ana Paula. A Constituição de 1988, a dignidade do ser humano e o direito à educação. In: ORTIZ, Maria Elena Rodriguez (Org.). Justiça Social: uma Questão de Direito. Rio de Janeiro: DP \& A Editora, 2004.

BOBBIO, Norberto. A era dos direitos. Rio de Janeiro: Campus, 1992.

BONAVIDES, Paulo. Curso de Direito Constitucional. 11. ed. São Paulo: Malheiros, 2001.

BRASIL. Constituição (1988). Constituição da República Federativa do Brasil de 1988. Brasília, DF: Senado Federal, 1988. Disponível em: <http://www.planalto.gov.br/ccivil_03/ constituicao/constituicao.htm>. Acesso em: 17 fev. 2013.

BRASIL. Lei no 9.394, de 20 de dezembro de 1996 - Lei de Diretrizes e Bases da Educação Nacional. Disponível em: $<$ http://portal.mec.gov.br/seed/arquivos/pdf/tvescola/leis/ lein9394.pdf>. Acesso em: 17 fev. 2013.

CHERQUES, Hermano Roberto Thiry. John Rawls: a economia moral da justiça. Revista Sociedade e Estado, v. 26, n. 3, p. 5510-563, set./dez. 2011.

DANIELS, Norman (Org.). Reading Rawls: critical studies on Rawls': A theory of justice. Stanford: Stanford University Press, 1989.

FELIPE, Sônia. Justiça: igualdade equitativa na distribuição das liberdades. In: FELIPE, Sônia. (Org.). Justiça como equidade: fundamentação, interlocuções polêmicas (Kant, Rawls, Habermas). Florianópolis: Insular, 1998.

FELIPE, Sônia. Rawls: uma teoria ético-política da justiça. In: OLIVEIRA, Manfredo Araújo de (Org.). Correntes Principais da Ética Contemporânea. Petrópolis, RJ: Vozes, 2000.

FLEISCHACKER, Samuel. Uma breve história da justiça distributiva. São Paulo: Martins Fontes, 2006.

FREEMAN, Samuel. Rawls. New York: Taylor \& Francis e-Library, 2007.

GALLO, Ś́lvio de Oliveira. A educação pública como função do Estado. Comunicações, v. 5, n. 1, p. 5-28, 1998. http:// dx.doi.org/10.15600/2238-121X/comunicacoes.v5n1p5-28.

GRUESO, Delfín Ignacio. Rawls: una hermenéutica pragmática. Cali: Universidad del Valle, 1997.

HORTA, José Silvério Baia. Direito à educação e obrigatoriedade escolar. Cadernos de Pesquisa, São Paulo, n. 104, p. 5-34, 1998.

JOHNSTON, James Scott. Rawls's Kantian educational theory. Educational Theory, v. 55, n. 2, p. 201-218, 2005. http:// dx.doi.org/10.1111/j.0013-2004.2005.00007.x

KANT, Immanuel. Pedagogía. 3 ed. Madrid: Akal, 2003.

KUKATHAS, Chandras; PETTIT, Philip. Rawls: "Uma Teoria da Justiça" e seus críticos. Gradiva: Lisboa, 1995.

MANDLE, Jon. Rawls's: A Theory of Justice - an introductio. New York: Cambridge University Press, 2009.

MARTIN, Rex. Rawls and rights. Lawrence: University Press of Kansas, 1985.

MESSEDER, Hamurabi. Entendendo a LDB. 2. ed. Rio de Janeiro: Elsevier, 2010.

MICHELMAN, Frank. Constitutional welfare rights and a Theory of Justice. In: DANIELS, Norman (Org.). Reading Rawls: critical studies on Rawls': a Theory of Justice. Stanford: Stanford University Press, 1989.
MICHELMAN, Frank. In pursuit of constitutional welfare rights: one view of Rawl's Theory of Justice. University of Pennsylvania Law Review, v. 121, p. 962-1012, 1973. http:// dx.doi.org/10.2307/3311279.

MICHELMAN, Frank. Welfare rights in a constitutional democracy. Washington University Law Quarterly, v. 1979, n. 3, p. 659-93, 1979.

MORAES, Alexandre de. Constituição do Brasil interpretada. São Paulo: Atlas, 2003.

PAIVA, Regina Garcia de. Direito educacional: do fato para o direito. In: TRINDADE, André (Org.). Direito Educacional: sob uma Ótica Sistêmica. 1. ed. Curitiba: Juruá, 2007.

RAWLS, John. A Theory of Justice. Cambridge: Harvard University Press, 2000.

RAWLS, John. Distributive justice. In: RAWLS, John. Collected Papers. Cambridge, Mass: Harvard University Press, 1999.

RAWLS, John. Justiça como equidade: uma reformulação. Tradução de Cláudia Berliner. São Paulo: Martins Fontes, 2003.

RAWLS, John. O liberalismo político. Tradução de Dinah de Abreu Azevedo. São Paulo: Ática, 2000.

RAWLS, John. Uma Teoria da Justiça. Tradução de Jussara Simões. São Paulo: Martins Fontes, 2009.

ROHLING, Marcos; VOLPATO DUTRA, Delamar José. O direito em "Uma Teoria da Justiça" de Rawls. Dissertatio (UFPel), v. 34, p. 63-89, 2011.

ROHLING, Marcos. A educação e a educação moral em "Uma Teoria da Justiça" de Rawls. Fundamento - Revista de Pesquisa em Filosofia, v. 4, n. 4, p. 125-149, jan.-jun. 2012 .

SACAVINO, Susana Beatriz. Direito humano à educação no Brasil: uma conquista para todos/as?. In: SILVEIRA, Rosa Maria Godoy; ALVES DIAS, Adelaide; GUERRA FERREIRA, Lucia de Fátima; PEREIRA DE ALENCAR, Maria Luiza; TAVARES Celma (Org.). Educação em Direitos Humanos: Fundamentos Teórico-Metodológicos. 1. ed. João Pessoa: Editora Universitária, 2007.

VALLE, Ione Ribeiro. Justiça na escola: das desigualdades justas à igualdade sem adjetivos!. In: VALLE, Ione Ribeiro; SILVA, Vera Lúcia Gaspar da; DAROS, Maria das Dores (Org.). Educação Escolar e Justiça Social. Florianópolis: Nup, 2010.

VAN PARIJS, Philippe. O que é uma sociedade justa? introdução à prática da filosofia política. Tradução de Cintia Ávila de Carvalho. São Paulo: Ática, 1997.

WEBER, Eric Thomas. Rawls, Dewey, and Constructivism. On the Epistemology of Justice. London: Continuum, 2010.

WEBER, Thadeu. A ideia de um "Mínimo Existencial" de J. Rawls. Kriterion, Belo Horizonte, v. 54, n. 127, p. 197-210, jun. 2013. http://dx.doi.org/10.1590/S0100-512X20130001 00011 .

WEITZ, Betty. Equality and justice in education: Dewey and Rawls. Human Studies, v. 16, n. 4, p. 421-34, 1993. http:// dx.doi.org/10.1007/BF01323026. 


\section{NOTAS}

${ }^{1}$ É verdade que geralmente se entende por educação a mera formação ou a simples qualificação. Esse, contudo, é apenas um entre tantos sentidos usados no que se refere à educação. $\mathrm{O}$ que se quer dizer é que conforme se entenda a educação, mais precisamente se reconhece um direito à mesma. Disso, o direito à educação é conecto ao entendimento do que seja educação.

2 Projeto racional de vida é um termo utilizado por Rawls para falar dos planos de vida. A pessoa humana é caracterizada por Rawls como sendo portadora de duas capacidades essenciais, quais sejam: i) a capacidade de concepção de bem; e ii) a capacidade de senso de justiça. De posse dessas duas capacidades, os cidadãos, dentro e através da sociedade, concebida como um sistema de cooperação social, empenhar-se-iam em realizar um projeto, ou plano racional de vida. A racionalidade aqui significa o desejo dos meios para a consecução dos fins. Assim posto, a educação é fundamental para dar ao indivíduo a possibilidade de autodeterminar-se perante os variados e possíveis planos racionais de vida. Cf. RAWLS, Uma Teoria da Justiça. Doravante, utilizar-se-á TJ para se referir a A Theory of Justice (Revised Edition), Cambridge: Harvard University Press, 2000 [trad. Bras: Jussara Simões. São Paulo: Martins Fontes, 2009] e $P L$ para Political Liberalism, New York, NY: Columbia University Press, 1993 [trad. Bras.: Dinah de Abreu Azevedo. São Paulo: Ática, 2000].

3 A ideia e o entendimento do que seja o direito educacional são inspirados em PAIVA, 2007. Em geral, a autora define o direito educacional como "o conjunto de normas que disciplina e regula a atividade educacional. Em outras palavras, é o ramo do Direito que trata da educação e das relações que nela se estabelecem". (PAIVA, 2007, p. 75).

4 A influência do pensamento de Rawls no pensamento social, político, ético e jurídico contemporâneo é imprecisável e, inegavelmente, muito por conta do alcance desempenhado por sua teoria. Suas ideias revolucionaram as práticas políticas de diversos países desde que seu opus magnum, Uma Teoria da Justiça, foi lançado em 1971. Ao longo das décadas posteriores, discutiu e revisou algumas de suas ideias, o que implicou a publicação de outra importante obra, $O$ Liberalismo Político. Quanto às práticas políticas internacionais, desenvolveu posições em $O$ Direito dos Povos. Rawls influenciou muitos intelectuais, pensadores e juristas contemporâneos, entre os quais merecem destaque, Ronald Dworkin, Thomas Pogge, Thomas Scanlon, entre outros. Participaram de seu círculo de discussão, até sua morte, em 2002, figuras como Hart, Kohlberg, Habermas, Sandel, Walzer, entre outros.

5 É interessante observar, conforme disposto no artigo 5o, da Lei no 9.394 (LDB), que não apenas o indivíduo pode requerer legitimamente a garantia do acesso à educação. Esse artigo reza que "o acesso ao ensino fundamental é direito público subjetivo, podendo qualquer cidadão, grupo de cidadãos, associação comunitária, organização sindical, entidade de classe ou outra legalmente constituída e, ainda, Ministério Público, acionar o Poder Público para exigi-lo".

${ }^{6}$ No que se refere ao direito educacional, bem como analogicamente aos outros ramos do Direito, há uma hierarquia legislativa e administrativa que obedece à seguinte: (i) Constituição Federal - na qual se encontra o nascedouro do direito à educação e do dever para com a educação, assim como os princípios norteadores da tarefa educacional; (ii) Constituições Estaduais - as quais devem se alinhar às regras basilares e orientadoras da prática educacional de cada um dos Estados-partes da Federação, de acordo com os princípios da Lei Maior da República; (iii) leis complementares, que traçam as bases da educação nacional de tal modo a se ter uma unidade na condução da atividade educacional [é importante dizer que a Lei de Diretrizes e Bases da Educação Nacional, a LDB, é uma lei específica requerida pela CF88, que estabelece a cooperação entre a União, os Estados, o Distrito Federal e os municípios; dessa feita, pode ser vista, como de fato o é, uma extensão da Constituição]; (iv) leis ordinárias, que dispõem sobre as normas gerais e abstratas, disciplinando relações no âmbito nacional; (v) decretos, portarias, regulamentos que explicitam a aplicação das disposições gerais, aclarando, nesse sentido, o mandamento das leis e determinando a sua fiel execução; (vi) exame dos votos exarados pelos membros de tribunais nos quais são detectados princípios e normas que podem servir de quadro de referência para dirimir as contendas que brotam no âmbito educacional; e, por fim, (vii) pareceres, resoluções, deliberações e indicações do Conselho Nacional de Educação, da Secretaria de Ensino Superior do Ministério de Educação e dos Conselhos Estaduais de Educação que enunciam as normas disciplinadoras da atividade educacional (PAIVA, 2009, p. 69).

${ }^{7}$ BRASIL, Constituição da República Federativa do Brasil, promulgada em 05/10/1988. Doravante, CF88.
${ }^{8}$ Como a autora em questão faz notar, nos centros urbanos, melhores condições de salários e empregos exigem níveis cada vez mais elevados de escolaridades e o Estado deve estar comprometido com essa finalidade. Assim, assegurar o ensino fundamental a todos provavelmente não seja suficiente para todos os projetos e para a capacidade de alguns (BARCELLOS, 2004, p. 157-8).

9 Tendo em vista a importância da questão para a temática em tela, deve-se dizer que alguns autores, entre os quais Arango, concebem que, para Rawls, tal como a teoria da justiça como equidade em $T J$, os direitos e, nesse caso, direitos constitucionais, devem ser entendidos como as liberdades constitucionais das quais Rawls fala, referindo-se ao primeiro princípio. Este é formulado em termos de um direito moral básico que justifica os direitos constitucionais na estrutura básica da sociedade justa. Dessa sorte, a inclusão de uma carta de direitos (em resumo, abarcando os convencionais direitos civis e políticos) na Constituição é uma forma de institucionalizar o primeiro princípio de justiça numa determinada sociedade (ARANGO, 2005, p. 142-3).

${ }^{10}$ No âmbito da educação, existe um debate vivo sobre a questão do mérito e dos seus efeitos na vivência escolar. Entre esses teóricos, além da importância teórica que a obra de Rawls suscitou em termos de políticas educacionais atuais, como as medidas reparadoras ou compensatórias, destaca-se a figura de Dubet, o qual, entre outras coisas, ressalta que um sistema escolar justo não se preocupa apenas com uma competição ideal, mas também com a forma pela qual se tratam os alunos mais fracos ou menos bons. Dubet milita no sentido de pensar as práticas educacionais justas e, nesse sentido, questiona o papel atribuído ao mérito, o qual, no entanto, não é descartado por ele, tendo em vista ter um papel relevante na questão das desigualdades justas. Sobre essa questão, ver: VALLE, Justiça na Escola: das Desigualdades Justas à Igualdade sem Adjetivos!, p. 19-48, In: VALLE; SILVA \& DAROS (Orgs.). Educação Escolar e Justiça Social. Florianópolis: Nup, 2010.

${ }^{11}$ É verdade que isso não implica sua não inclusão num texto constitucional. O que se quer pontuar é que não há a possibilidade de sua igual distribuição, como é o caso, na CF88, das cláusulas pétreas, nos moldes dos requisitos do princípio da liberdade igual.

${ }^{12}$ Weber escreve um texto cuja ideia é a do mínimo existencial como condição de possibilidade para a realização dos direitos e liberdades fundamentais incluídos sob o primeiro princípio de justiça de Rawls. Weber afirma que a dignidade da pessoa humana, como preceito ético, exige do Estado a garantia de efetivação dos direitos dela decorrentes. Quando se fala juridicamente de um mínimo existencial, no fundo, estáse tratando de algo intrinsecamente ligado à realização dos direitos fundamentais, os quais representam a concretização do princípio da dignidade humana. Sendo assim, a ideia que norteia o mínimo existencial refere-se à preservação e à garantia das condições e exigências mínimas de uma vida digna. Ora, isso quer dizer que o direito ao mínimo está alicerçado no direito à vida e na dignidade humana (WEBER, 2013, p. 198-200)

${ }^{13}$ Entre as razões que Rawls arrola, merece destaque a da dificuldade para verificação e avaliação. Segundo o autor, é algo mais ou menos visível, diante dos arranjos constitucionais e da forma pela qual se pode vê-los funcionar na prática, a medida de satisfação dos elementos constitucionais essenciais que abarcam as liberdades constitucionais. No entanto, isso não se verifica com os objetivos dos princípios que abrangem as desigualdades sociais e econômicas, porquanto envolverem complicadas inferências e juízos intuitivos que requerem a avaliação de informações sociais e econômicas complexas sobre tópicos mal compreendidos. Disso, segue-se que é de se esperar que existam mais acordos no que se refere aos princípios que dizem respeito às liberdades e aos direitos fundamentais do que acerca do que aqueles voltados para a justiça social e econômica, embora sejam todos eles discutidos em termos de valores políticos (RAWLS, 2000, p. 279-80).

${ }^{14}$ Para fins de clareza, cabe dizer que Michelman, num artigo de 1979, ao qual Rawls refere-se, afirmava que ele esquecera-se dos direitos sociais constitucionais porque trabalhava tendo em mente uma sociedade bem ordenada. No entanto, há a necessidade de que estes sejam respeitados e integrados à Constituição. Em geral, essa questão diz respeito à distinção que Michelman faz entre direitos sociais constitucionais (garantias específicas, cuja finalidade é assegurar a prática de outras liberdades e direitos) e direitos de ingresso mínimo (direitos contra uma desigualdade excessiva ou desnecessária de riqueza ou afins). É verdade que, em sociedades reais e não ideais, os direitos sociais não são apenas importantes, mas essenciais, de tal modo a serem reconhecidos em nível constitucional. Cf. MICHELMAN, 1973, p. 966-1001; 1979, p. 680-5. Ver também ARANGO, 2003, p. 150-2. 
${ }^{15}$ Cabe recordar que os princípios de justiça são escolhidos em função da capacidade de proporcionar, em maior quantidade, bens primários para todos de um modo mais equitativo.

16 À guisa de complemento, é oportuno dizer que a legislação brasileira prima pela equidade do desfrute. Como indica Barcellos, no caso de o poder público não dispor de vagas para o acesso à formação escolar em escolas públicas, pode fazê-lo recorrendo às instituições privadas. Como a autora advoga, nada justifica que o indivíduo que obteve judicialmente o direito à formação seja mais bem aquinhoado do que aquele que frequentou escolas públicas. O padrão e o custeio, no entanto, devem ser equânimes em relação àqueles das escolas públicas. E mais: o direito à educação compõe o núcleo da dignidade humana, pelo que, no caso brasileiro, é oponível aos poderes constituídos. Cf. BARCELLOS, 2004 p. $160-1$.

${ }^{17}$ KANT, 2003, p. 31. Tradução livre de: Únicamente por la educación el hombre puede llegar a ser hombre. No es, sino lo que la educación le hace ser.

Artigo recebido em janeiro 2014.

Aprovado em maio 2015. 